\title{
SPECIES ASSIGNATION OF LEISHMANIA FROM HUMAN AND CANINE AMERICAN TEGUMENTARY LEISHMANIASIS CASES BY MULTILOCUS ENZYME ELECTROPHORESIS IN NORTH ARGENTINA
}

\author{
JORGE D. MARCO, PAOLA A. BARROSO, MANUEL CALVOPIÑA, HIDEO KUMAZAWA, MASATO FURUYA, \\ MASATAKA KORENAGA, SILVANA P. CAJAL, MARÍA C. MORA, MARÍA M. J. REA, C. EDGARDO BORDA, \\ MIGUEL A. BASOMBRÍO, NÉSTOR J. TARANTO, AND YOSHIHISA HASHIGUCHI \\ Department of Parasitology, Kochi Medical School, Kochi University, Kochi, Japan; Instituto de Patología Experimental, Facultad de \\ Ciencias de la Salud, Universidad Nacional de Salta, Buenos Aires, Argentina; Consejo Nacional de Investigaciones Científicas y \\ Técnicas (CONICET), Buenos Aires, Argentina; Instituto de Enfermedades Tropicales, Sede Regional Orán, Universidad Nacional de \\ Salta, Salta, Argentina; Institute for Laboratory Animals, Kochi Medical School, Kochi University, Kochi, Japan; Centro Nacional de \\ Parasitología y Enfermedades Tropicales, Universidad Nacional del Nordeste, Corrientes, Argentina
}

\begin{abstract}
Sixteen Leishmania stocks, 15 isolated from patients with cutaneous (CL), mucocutaneous (MCL), or recurrent cutaneous leishmaniasis, plus one from a dog with CL in Salta and Corrientes Provinces, Argentina, were studied by multilocus enzyme electrophoresis. Thirteen of the stocks from humans were grouped in two zymodemes; nine termed as KMS 1, four as KMS 2, and assigned to Leishmania (Viannia) braziliensis. Two additional stocks from CL cases expressed a KMS 4 enzyme profile, corresponding to $L$. $(V$.) guyanensis. Although the parasites from the dog were also assigned to $L$. $(V$.) braziliensis, its zymodeme, KMS 3, was not expressed in any of the current human isolates. The characterization of Leishmania from a dog was done for the first time in Argentina. The importance of the intraspecific polymorphism in the induction of clinical forms and in the host-reservoir concept is briefly discussed, based on the zymodeme data of isolates from humans and dogs. The presence of $L$. (V.) guyanensis was confirmed in the country.
\end{abstract}

\section{INTRODUCTION}

American tegumentary leishmaniasis (ATL) is a group of zoonotic diseases widespread in 22 countries from Texas (USA) to northern Argentina. It is caused by flagellar protozoa belonging to the genus Leishmania ${ }^{1}$ in which a tremendous diversity or polymorphism has been found. ${ }^{2}$ The diseases caused by different species are distinct in their clinical manifestations, drug responses, and prognosis. Therefore, it is necessary to characterize and identify specifically the parasites obtained in each endemic area where a survey is taken. ${ }^{3}$ For this purpose, multilocus enzyme electrophoresis (MLEE) analysis has been recommended by the World Health Organization $(\mathrm{WHO}){ }^{4}$

In northern Argentina, some areas have been reported to be endemic for human and canine leishmaniasis. However, little is known about the causative agents, Leishmania spp., and the transmission cycles implicated there. Salta and Corrientes Provinces are endemic areas, where most of the clinical forms of human ATL showed single and multiple cutaneous (CL), mucocutaneous (MCL), or mucosal lesions (Borda $\mathrm{CE}$ and others, unpublished data). ${ }^{5,6}$ Vegetant nonulcerated lesions with metastasis to the lymph nodes and viscus (spleen) have also been described. ${ }^{7}$ As to the causative parasites, it was found that L. (Viannia) braziliensis was predominant in Salta Province, followed by L. (Leishmania) amazonensis, and $L$. (V.) guyanensis, though relatively few isolates were specifically characterized to date. ${ }^{2,8,9}$

Previously, we studied the clinical, parasitological, and serological characteristics of canine tegumentary leishmaniasis in Salta Province. Several observations from these works suggested that dogs might be considered as a susceptible host without having a principal role in the spread of the disease. ${ }^{10,11}$ However, any Leishmania stock was not isolated from dogs in this area before.

This paper reports the species attribution and the examinations of the relationship between Leishmania isolates from different clinical forms of human and canine ATL in northern Argentina, based on MLEE data; the first description of ca- nine Leishmania isolate in the country is herein provided. The relevance of the intraspecific polymorphism to the induction of different clinical forms, as well as its incidence in the hostreservoir concept, is briefly discussed.

\section{MATERIALS AND METHODS}

Parasites and study area. Sixteen stocks of Leishmania were included in this study. Fourteen of them, from 11 humans, and one stock from a dog were isolated in Salta Province, northwest Argentina. The remaining one was obtained from a patient in Corrientes Province, located in the northeast of Argentina. Their denomination, the clinical data of the host, and a description of the geographical origin are shown in Table 1 and Figure 1. The samples were taken from patients who were accessed in the four institutions, viz., the Instituto de Investigaciones en Enfermedades Tropicales, Subsede Orán, Universidad Nacional de Salta; the Dermatology Ward of Hospital del Milagro; the Dermatology and Otorhinolaryngology Wards of Hospital San Bernardo of Salta City; and Centro Nacional de Parasitología y Enfermedades Tropicales, Universidad Nacional del Nordeste, Corrientes City. A part of the current isolates was obtained from humans and canine cases during house-to-house visits.

All the referred patients, from whom Leishmania parasites were isolated from their lesions, were systemically treated for 25-30 days with $10-20 \mathrm{mg} \mathrm{d}^{-1} \mathrm{~kg}$ body $\mathrm{wt}^{-1}$ of pentavalent antimony for each cycle. In the cases of the incomplete clinical cure of lesion, another cycle of treatment or amphotericin $\mathrm{B}$ treatment was given. ${ }^{4}$ The clinical controls and treatment protocols were exclusively conduced for local physicians. The patients voluntarily consented to participate in this study, and the Bioethical Commission of Health Ministry of Salta Province approved the procedures.

Six WHO reference strains were included; $L$. (V.) braziliensis, MHOM/BR/75/M2904; L. (V.) panamensis, MHOM/PA/ 71/LS94; L. (V.) guyanensis, MHOM/BR/75/M4147; L. (L.) amazonensis, MHOM/BR/73/M2269; L. (L.) mexicana, 


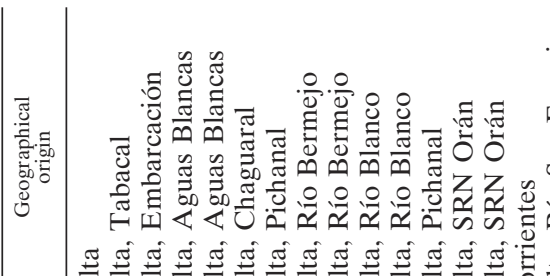

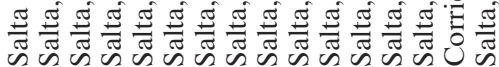

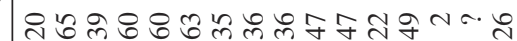

$\Sigma \Sigma \Sigma \Sigma \Sigma \Sigma \Sigma \Sigma \Sigma \Sigma \Sigma \Sigma \Sigma \Sigma \Sigma \Sigma \Sigma \Sigma$

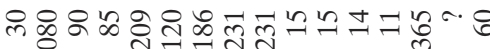

$\times$

范

踢

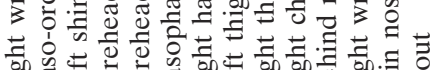

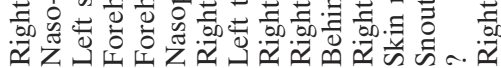

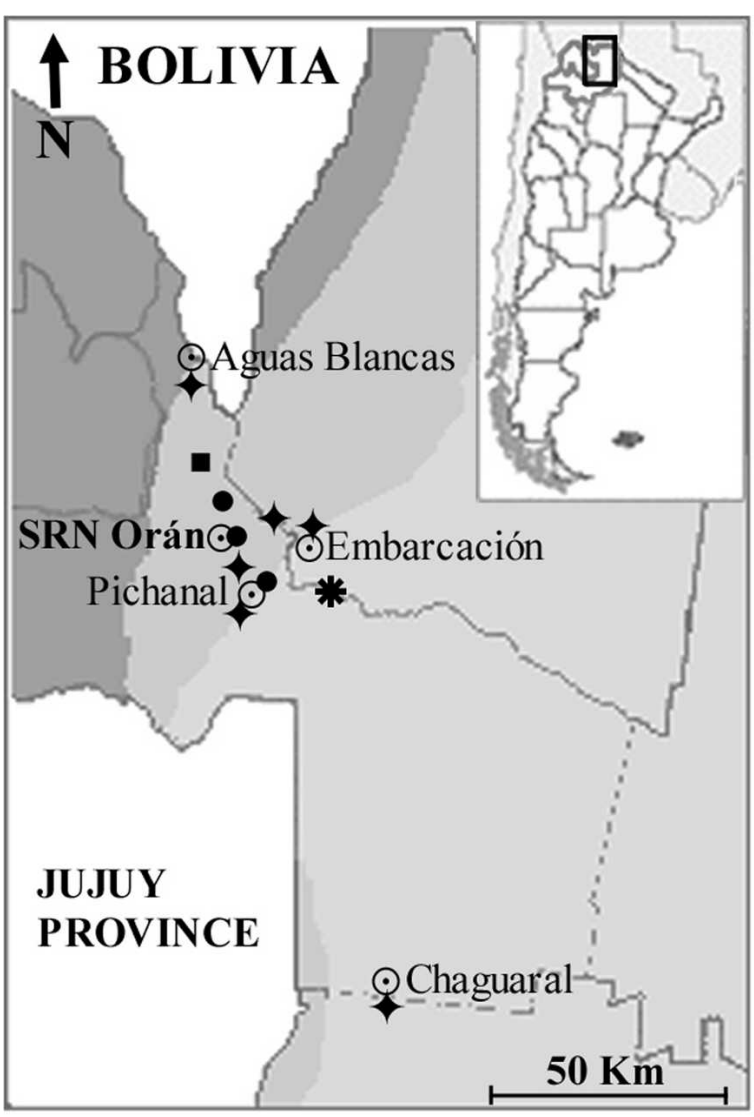

Figure 1. Map of the north of Salta Province, Argentina, showing phytogeographical locations of the zymodemes. Leishmania (Viannia) braziliensis: $\downarrow$ KMS 1, KMS 2, and KMS 3. L. (V.) guyanensis: * KMS 4. $\square$ Selva y Bosque Montano: Subtropical humid forest within 900-3000 m above sea level (m.a.s.l.). Annual precipitations (ann. prec.): 700-2000 mm. Annual mean temperature (AMT): $20^{\circ} \mathrm{C}$. $\square$ Selva de Transición: Subtropical humid forest within $340-700$ m.a.s.l. Ann. prec.: $700-1070 \mathrm{~mm}$. AMT: $20^{\circ} \mathrm{C}(\mathrm{Co}-$ mité MAB Argentino, unpublished data). $\square$ Chaco Occidental: Xerophytic lowland plain and semiarid climate within 300 m.a.s.l. (max). Ann. prec.: $550 \mathrm{~mm}$. AMT: $23^{\circ} \mathrm{C}$ (Gasparri I and others, unpublished data).

MNYC/BZ/62/M379; and $L$. (L.) chagasi (syn. Infantum), $\mathrm{MHOM} / \mathrm{BR} / 74 / \mathrm{M} 2682$.

Isolation and mass cultivation. Thirteen stocks were obtained by aspiration of the CL or MCL lesion edges of humans or dogs, using a syringe with $0.5 \mathrm{~mL}$ of sterile proline balanced salts solution (PBSS) containing $100 \mathrm{U} / \mathrm{mL}$ penicillin and $50 \mu \mathrm{g} / \mathrm{mL}$ streptomycin (P E). The material aspirated was inoculated into Difco blood agar (USMARU) medium containing $20 \%$ of defibrinated rabbit blood. ${ }^{12,13}$ One milliliter of PBSS with P E was added after 4 days of incubation at $23^{\circ} \mathrm{C}$. A final volume of liquid phase of $2 \mathrm{~mL}$ was reached after 4 days more. One stock (JDM1) was obtained by an inoculation of the aspirated material into a footpad of a golden hamster (Mesocricetus auratus). Two months after the inoculation, the footpad tissue was aseptically removed, homogenized, and inoculated into five culture tubes containing $2 \mathrm{~mL}$ of sterile liver infusion tryptose medium supplemented with P E and $20 \%$ heat-inactivated fetal bovine serum (hiFBS). ${ }^{12}$ The remaining two stocks (AZ3, LBC1) were isolated by skin biopsy of the cutaneous lesion edges and transferred to Novy-Nicolle-Mac Neal (NNN) medium. 
The cultures were examined regularly from the 4th to 30th day of inoculation. When promastigotes were not found, the culture was gently centrifuged and the used USMARU medium was replaced by a fresh one after washing the pellet twice in $5 \mathrm{~mL}$ of PBSS.

For mass cultivation, $1 \mathrm{~mL}$ of promastigotes-culture in logarithmic phase was transferred to $6 \mathrm{~mL}$ RPMI 1640 medium supplemented with $10 \%$ of hiFBS. The culture volume was duplicated once every 2 days to reach a volume of $70 \mathrm{~mL}$ and incubated for a maximum of 12 days. The promastigotes were harvested by centrifugation at $10,000 \mathrm{rpm}$ for 15 minutes at $4^{\circ} \mathrm{C}$, after washing (2,500 rpm, 20 minutes) 3 times with sterile $0.85 \% \mathrm{NaCl}$ solution. The pellets were stored in a deep freezer $\left(-80^{\circ} \mathrm{C}\right)$ until use.

Sample preparation. The soluble enzyme extracts were obtained by lysis of the pellets in a double volume of stabilizer solution containing $2 \mathrm{mM}$ dithiotreitol, $2 \mathrm{mM} \varepsilon$-aminocaproic acid, and 2 mM EDTA. After 3 cycles of freezing and thawing, the supernatants obtained by centrifugation at 27,000 rpm at $4{ }^{\circ} \mathrm{C}$ were aliquoted and stored at $-80^{\circ} \mathrm{C}^{12}$

Enzyme electrophoresis. Electrophoresis and staining procedures were performed on cellulose acetate support (Sebiagel; Moulineux, France) following the methods described by Kreutzer and Christensen and by Evans, with slight modifications. ${ }^{12,14}$ Pictures of gels were taken with a Kodak EDAS 290 digital camera. Each enzyme extract was analyzed at least twice by 11 enzyme systems for 12 putative enzymatic loci: alanine aminotransferase (E.C.2.6.1.2, ALAT), aspartate aminotransferase (E.C.2.6.1.1, ASAT), glucose-6-phosphate dehydrogenase (E.C.1.1.1.49, G6PDH), 6-phosphogluconate dehydrogenase (E.C.1.1.1.44, 6GPDH), glucose-phosphate isomerase (E.C.5.3.1.9, GPI), malate dehydrogenase (E.C.1.1.1.37, MDH), malic enzyme (E.C.1.1.1.40, ME), mannose-phosphate isomerase (E.C.5.3.1.8, MPI), nucleoside hydrolase (inosine) (E.C.2.4.2, $\mathrm{NH}_{\mathrm{i}} 1$ and $\mathrm{NH}_{\mathrm{i}} 2$ ), phosphoglucomutase (E.C.2.7.5.1, PGM), and pyruvate kinase (E.C.2.7.1.40, PK).

Data analysis. The distance that each reproducible enzyme band migrated from the origin (anode) was measured. The bands were numerated from the fastest (the nearest one to the cathode) to the slowest for each enzyme gel or zymogram. The obtained set of bands defined an electrophoretic profile for each extract. Stocks with the same profile were grouped in the same zymodeme ${ }^{2}$; the species attribution was made comparing the profiles with the WHO reference Leishmania strains. To examine the relationship between the zymodemes, Jaccard distances (JD) were obtained for all pairwise comparisons, ${ }^{15}$ a distance matrix was built and transformed into a phenogram by the unweighted pair group method using the MEGA version 2.1 Software. ${ }^{16}$

\section{RESULTS}

Fourteen stocks, included the isolate from the dog were assigned by MLEE analysis of 12 enzymatic loci to $L$. ( $V$.) braziliensis and two to L. (V.) guyanensis (Table 1; Figure 2A). No L. (L.) amazonensis was isolated from any patient. For the $L$. $(V$.) braziliensis stocks, the isolates from humans were grouped in 2 zymodemes, KMS 1 and KMS 2, differing in 1 locus, MDH (Figure 2B). The stock from the dog was assigned to another zymodeme, KMS 3 that differed from KMS 1 only in 1 locus, ME (Figure 2C), and from KMS 2 in 2 loci, ME and MDH (Figures 2B and 2C).

Both $L$. $(V$.$) guyanensis isolates were grouped in the same$ zymodeme, KMS 4, that included the reference strain. Two loci, G6PDH and 6GPDH, distanced them from the $L$. (V.) panamensis reference strain. The enzymatic profiles are shown in Table 2. The relationship between the zymodemes is shown in a phenogram (Figure 3). Over a JD of 0.9, 2 clusters, corresponding to the subgenera Viannia and Leishmania, can be distinguished. The zymodemes KMS 1 and KMS 2 were more closely related with each other $(\mathrm{JD}=0.056)$ than with KMS $3(\mathrm{JD}=0.126)$ and with $L$. (V.) braziliensis reference strains $(\mathrm{JD}=0.161)$. The JD observed between KMS 4 and L. (V.) panamensis reference strains was 0.222 .

In three different cases of the current study, two stocks each were isolated from the same patient (MHOM/AR/02/ MAS5, MHOM/AR/03/MRO2, and MHOM/AR/03/HNO3); they expressed the same enzymatic profile for each pair, without demonstrating the possibility of co-infection with multiple zymodemes and/or species of Leishmania parasite (Table 1; Figure 3).

\section{DISCUSSION}

Leishmania species identification is essential for clinical or epidemiologic surveys because of the diversity found among

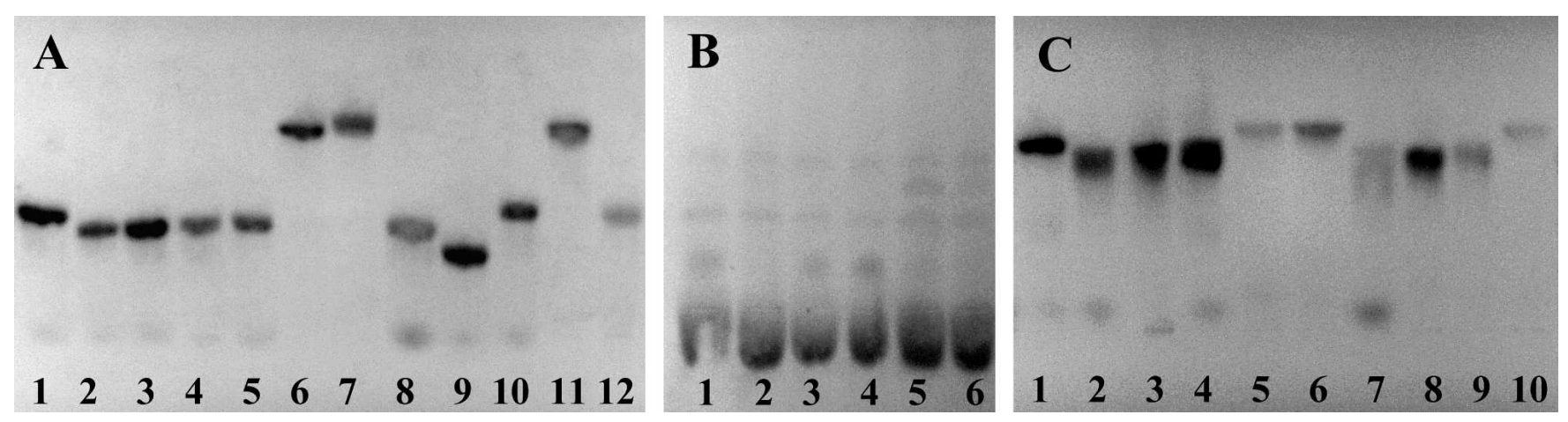

FIGURE 2. A, 6-Phosphogluconate dehydrogenase (6PGDH) zymogram. Lanes 1 and 12, KMS 4; Lane 2, KMS 3; Lanes 3 and 4, KMS 1; Lane 5, KMS 2; Lane 6, Leishmania (Leishmania) mexicana ref. strain; Lane 7, L. (L.) amazonensis ref. strain; Lane 8, L. (Viannia) braziliensis ref. strain; Lane 9, L. (V.) panamensis ref. strain; Lane 10, L. (V.) guyanensis ref. strain, and Lane 11, L. (L.) chagasi ref. strain. B, Malate dehydrogenase (MDH) zymogram. Lane 1, KMS 3; Lanes 2, 3, and 4, KMS 1; and Lanes 5 and 6, KMS 2. C, Malic enzyme (ME) zymogram. Lane 1, KMS 3; Lanes 2 and 3, KMS 1; Lane 4, KMS 2; Lane 5, L. (L.) mexicana ref. strain; Lane 6, L. (L.) amazonensis ref. strain; Lane 7, L. (V.) braziliensis ref. strain; Lane 8, L. (V.) panamensis ref. strain; Lane 9, L. (V.) guyanensis ref. Strain; and Lane 10, L. (L.) chagasi ref. strain. 
TABLE 2

Enzymatic profiles for Argentinian stocks and WHO reference strain zymodemes

\begin{tabular}{|c|c|c|c|c|c|c|c|c|c|c|c|c|}
\hline \multirow[b]{2}{*}{ Zymodeme } & \multicolumn{12}{|c|}{ Enzymatic loci } \\
\hline & ALAT & ASAT & G6PDH & 6GPDH & GPI & $\mathrm{MDH}$ & $\mathrm{ME}$ & MPI & $\mathrm{NH}_{\mathrm{i}} 1$ & $\mathrm{NH}_{\mathrm{i}} 2$ & PGM & PK \\
\hline KMS 1 & 4 & 2 & 2 & 3 & 1,2 & $1,4,5$ & 3 & $3,4,5$ & 1 & 2 & 2 & 2 \\
\hline KMS 2 & 4 & 2 & 2 & 3 & 1,2 & $1,2,4,5$ & 3 & $3,4,5$ & 1 & 2 & 2 & 2 \\
\hline KMS 3 & 4 & 2 & 2 & 3 & 1,2 & $1,4,5$ & 2 & $3,4,5$ & 1 & 2 & 2 & 2 \\
\hline KMS 4 & 3 & 1 & 1 & 2 & 1,2 & 1,6 & 3 & $4,5,6$ & 2 & 1 & 3 & 1 \\
\hline KMS 5 & 1 & 3 & 3 & 1 & 4 & 2,5 & 1 & 1 & 2 & 3 & 1 & 3 \\
\hline KMS 6 & 2 & 4 & 2 & 1 & 3 & 4 & 1 & 1 & 2 & - & 2 & 3 \\
\hline KMS 7 & 4 & 2 & 2 & 3 & 1,2 & 2,5 & 3 & $3,4,5$ & 1 & 2 & 2 & 2 \\
\hline KMS 8 & 3 & 1 & 2 & 4 & 1,2 & 1,6 & 3 & $4,5,6$ & 2 & 1 & 3 & 1 \\
\hline KMS 9 & 2 & 3 & 3 & 1 & 3 & 3 & 2 & 2 & 2 & - & 3 & 2 \\
\hline
\end{tabular}

ALAT $=$ alanine aminotransferase; ASAT $=$ aspartate aminotransferase; G6PDH $=$ glucose-6-phosphate dehydrogenase, $6 \mathrm{GPDH}=6$-phosphogluconate dehydrogenase; GPI $=$ glucosephosphate isomerase; $\mathrm{MDH}=$ malate dehydrogenase, $\mathrm{ME}=$ malic enzyme, $\mathrm{MPI}=$ mannose-phosphate isomerase; $\mathrm{NH}_{\mathrm{i}} 1$ and $\mathrm{NH}_{\mathrm{i}} 2=$ nucleoside hydrolase (inosine); $\mathrm{PGM}=$ phosphoglucomutase; PK = pyruvate kinase; KMS = Kochi Medical School. KMS 1 (MHOM/AR/99/AZ3, MHOM/AR/02/NSS3, MHOM/AR/02/RLS6, MHOM/AR/02/MAS5 a and b, MHOM/AR/03/ AAS4, MHOM/AR/03/OLO1, and MHOM/AR/03/MRO2 a and b in Table 1), KMS 2 (MHOM/AR/03/HNO3 a and b, MHOM/AR/03/FDO4, and MHOM/AR/03/CFO5) and KMS 3 (MCAN/AR/02/LPO1) correspond to Leishmania (Viannia) braziliensis from Argentina. KMS 4: L. (V.) guyanensis ref. strain and two current stocks (MHOM/AR/98/LBC1 and MHOM/AR/ 99/JDM1); KMS 5: L. (Leishmania) mexicana ref. strain; KMS 6: L. (L.) amazonensis ref. strain; KMS 7; L. (V.) braziliensis ref. strain; KMS 8: L. (V.) panamensis ref. strain; KMS 9: L. (L.) chagasi (syn. infantum) ref. strain.

this genus. ${ }^{3}$ In this work, $L(V$.$) braziliensis was incriminated$ as a causative agent of three different clinical forms of ATL, viz., CL, MCL, and RCL (recurrent cutaneous leishmaniasis) and involved in failure of treatment with pentavalent antimony drug. Leishmania (V.) braziliensis was the predominant species in Salta Province, concordant with previous studies in which the samples were taken mainly from CL cases. ${ }^{8,9}$

Although many factors are responsible for the clinical expression of Leishmania infection, ${ }^{17}$ it has recently been reported that intraspecific polymorphism in $L$. (V.) braziliensis species may be related to specific clinical forms of ATL. ${ }^{18}$ In the current study, both of the $L$. (V.) braziliensis zymodemes, KMS 1 and KMS 2, were found to have an ability to metastasize to mucocutaneous tissues and lymph nodes. However, we could not exclude the possibility that they have a tropism for different tissues, such as mucosa or skin and lymph nodes. Again, the main zymodeme, KMS 1, was isolated from both MCL and CL cases; the other zymodeme, KMS 2, is conformed for isolates that are able to infect the lymph node and induce recurrent cutaneous lesions far from the original scar.

Leishmania $(V$.$) guyanensis (zymodeme KMS 4) was iso-$ lated from patients with CL in two different geographic regions, Salta in the northwest and Corrientes in the northeast of Argentina. The same zymodeme grouped these stocks and WHO reference strain, confirming the homogeneity previously reported for this species in other areas of different countries. ${ }^{2,19}$ The current result confirms the presence of this species in Argentina, which was reported for the first time in 1987 from a patient in the same endemic area, Orán, Salta. ${ }^{2}$

Recently, it has been proposed that L. (V.) guyanensis and

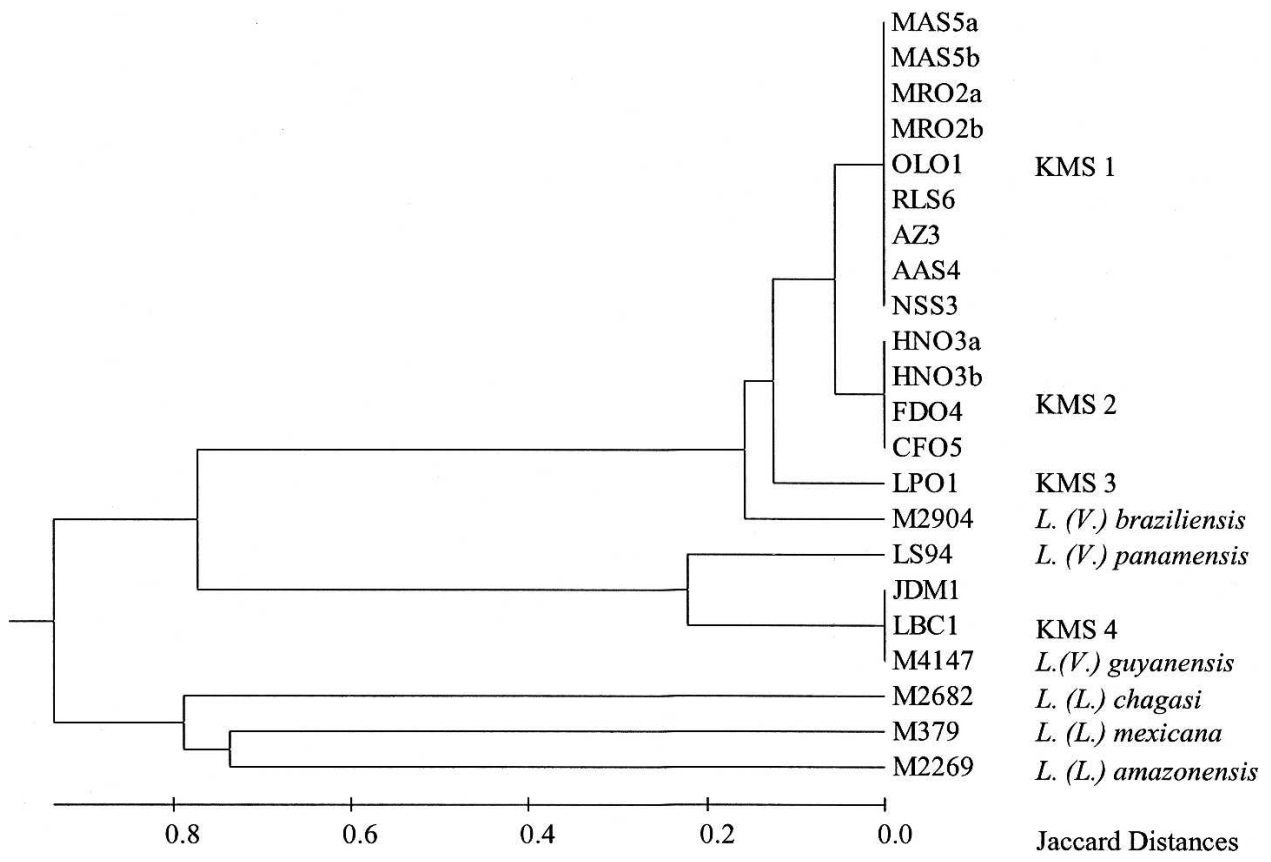

FIGURE 3. Relationship among 16 Argentinian Leishmania stocks from 12 patients (MAS5a, MAS5b, MRO2a, MRO2b, OLO1, RLS6, AZ3, AAS4, NSS3, HNO3a, HNO3b, FDO4, CFO5, JDM1, and LBC1; a, b mean different isolates from the same patient), a dog (LPO1), and WHO reference strains (M2904, LS94, M4147, M2682, M379, and M2269). The phenogram was built by the UPGMA method from the Jaccard distances calculated. 
L. (V.) panamensis should be considered as a unique clade based on the discrete typing unit concept. ${ }^{15}$ In this study, only two loci showed different characters between them, reaching a relatively small degree of distance $(\mathrm{JD}=0.222)$. Such a difference may not be enough to separate them as distinct species. Nevertheless, the factors that control the species diversity within the genus Leishmania remain unknown. A better understanding of taxonomic units for Leishmania will come when we understand what controls their distribution. ${ }^{20}$

In a previous study of 208 dogs examined, 41 (19.7\%) presented leishmanial lesions, and $14(45.2 \%)$ out of 31 lesions studied intensively were positive for Leishmania amastigotes, but no parasite isolation in vitro was possible. ${ }^{11}$ In this work, therefore, we are reporting for the first time the isolation and characterization of Leishmania from dogs. Although the species involved was L. (V.) braziliensis, its zymodeme was not expressed by any of the isolates from humans. To incriminate a reservoir host, the parasites isolated from the reservoirs must be indistinguishable from those of man. ${ }^{4}$ This becomes especially important in the case of clades of parasites, such as L. (V.) braziliensis, in which their heterogeneity and plasticity have been demonstrated. ${ }^{17,19,20}$ Although more isolates from dogs need to be analyzed, this observation adds a point of discussion on whether the animal has a principal role as a reservoir of this disease, even when its prevalence is relatively high in the endemic area. In Minas Gerais State, Brazil, an intraspecific variation among $L$. (V.) braziliensis from dogs was described. ${ }^{21}$ On the other hand, in Três Braços, Brazil, two stocks isolated from dogs were shown to be indistinguishable from 15 isolates from humans by isoenzyme profiles. ${ }^{22}$ Furthermore, although $L$. (V.) braziliensis was found infecting dogs and other domestic animals in the endemic areas of different countries, the stocks characterization had reached, analyzing a limited number of enzymes. ${ }^{23,24}$ Under these circumstances, a generalization about the indistinguishableness among $L$. (V.) braziliensis isolated from humans and dogs cannot be done as has been suggested. ${ }^{25}$ Therefore, in the future, it should be proved in each study area, examining enough materials (human and dog isolates) by suitable techniques for the analysis.

The geographic origin of the zymodemes in the current study suggests that both phytogeographical areas, Selva de Transición and Chaco Occidental, are possible transmission places for Leishmania (V.) spp. in Salta Province. Particularly the same zymodeme of $L$. (V.) braziliensis, KMS 1, was found in both zones. Considering the zoonotic characteristic of ATL, this fact triggers questions such as if the same transmission cycle exists in both areas, is it related to the mobility and the ability of the reservoirs to colonize different environment. Therefore, a better understanding of the disease will be obtained when the transmission cycles have been disclosed in the areas.

Thus, the current data on the zymodemes from humans and dogs will give important information on the causative agents circulating in and around the endemic areas. By performing further analysis using more stocks from humans, it would be possible to disclose the relationships between the clinical features and the zymodeme patterns in the country.

Received June 9, 2004. Accepted for publication August 23, 2004.

Acknowledgments: We are grateful to the physicians and personnel of the Dermatology Ward of Hospital del Milagro and the Dermatology and Otorhinolaryngology Wards of Hospital San Bernardo of Salta City for the recruitment of the patients. We also thank Pedro Rueda, Hilda de Fillipi, Héctor Romero, Marisa Juarez, Federico Ramos, and Ricardo Rossi for their technical support and Patricio Diosque and Marcelo Padilla for their contributions and valuable comments.

Financial support: This study was supported by the Ministry of Education, Science, Culture and Sports of Japan (grant no. 14256002).

Authors' addresses: Jorge D. Marco, Paola A. Barroso, Manuel Calvopiña, Hideo Kumazawa, Masataka Korenaga, and Yoshihisa Hashiguchi, Department of Parasitology, Kochi Medical School, Kochi University, Kohasu, Oko Cho, Nankoku Shi, Kochi Ken, 783-8505 Japan, Telephone/Fax: +8188880 2415. Silvana P. Cajal and Néstor J. Taranto, Instituto de Enfermedades Tropicales, Sede Regional Orán, Universidad Nacional de Salta, Alvarado 751, San Ramón de la Nueva Orán, (4530) Salta, Argentina, Telephone/Fax: +54 3878 421924. Masato Furuya, Institute for Laboratory Animals, Kochi Medical School, Kochi University, Kohasu, Oko Cho, Nankoku Shi, Kochi Ken, 783-8505 Japan, Telephone: +8188880 2434, Fax: +81 88 880 2436. María C. Mora and Miguel A. Basombrío, Instituto de Patología Experimental, Facultad de Ciencias de la Salud, Universidad Nacional de Salta, Buenos Aires 177, (4400) Salta, Argentina, Telephone/Fax: +54 387 4255333. María M. J. Rea, C. Edgardo Borda, Centro Nacional de Parasitología y Enfermedades Tropicales, Facultad de Medicina, Universidad Nacional del Nordeste, Santa Fe 1432, (3400) Corrientes, Argentina, Telephone/Fax: +54 3783425484.

Reprint requests: Jorge D. Marco, Department of Parasitology, Kochi Medical School, Kochi University, Kohasu, Oko Cho, Nankoku shi, Kochi Ken, 783-8505 Japan, Telephone/Fax: +81 88880 2415, E-mail: marcojd@med.kochi-ms.ac.jp.

\section{REFERENCES}

1. Herwaldt BL, 1999. Leishmaniasis. Lancet 354: 1191-1199.

2. Cupolillo E, Grimaldi G Jr, Momen H, 1994. A general classification of New World Leishmania using numerical zymotaxonomy. Am J Trop Med Hyg 50: 296-311.

3. Grimaldi G Jr, Tesh RB, 1993. Leishmaniases of the New World: current concepts and implications for future research. Clin $\mathrm{Mi}$ crobiol Rev 6: 230-250.

4. World Health Organization, 1990. Control of the Leishmaniasis. Technical Report Series 793. Geneva: WHO, 21-25.

5. Bernasconi VE, 1928. Contribución al estudio de la distribución geográfica de la leishmaniosis en la República Argentina. Bol Inst Clin Quirug Bs As 15: 325-328.

6. Sosa Estani S, Campanini A, Sinagra A, Luna C, Peralta M, Coutada V, Medina L, Riarte A, Salomón D, Gomez A, Segura EL, 1998. Características clínicas y diagnostico de la leishmaniasis mucocutánea en pacientes de un área endémica de Salta. Medicina 58: 685-691.

7. Borzone RA, 1928. Leishmaniosis tegumentaria americana vegetante con localizaciones viscerales. Bol Inst Clin Quirug Bs As 15: 329-333.

8. Segura EL, Juan N, Piquin ALM, Cuba Cuba CA, Abramo Orrego L, Mc Mahon-Pratt D, Montamat EE, Momen H, Grimaldi G Jr, 2000. Molecular and biologic characterization of Leishmania parasites implicated in an epidemic outbreak in northwestern Argentina. Parasitol Res 86: 504-508.

9. Frank FM, Fernandez MM, Taranto NJ, Cajal SP, Margni RA, Castro E, Thomaz-Soccol V, Malchiodi EL, 2003. Characterization of human infection by Leishmania spp. in the Northwest of Argentina: immune response, double infection with Trypanosoma cruzi and species of Leishmania involved. Parasitology 126: 31-39.

10. Marco JD, Padilla AM, Diosque P, Fernández MM, Malchiodi EL, Basombrío MA, 2001. Force of infection and evolution of lesions of canine tegumentary leishmaniasis in Northwestern Argentina. Mem Inst Oswaldo Cruz 96: 649-652.

11. Padilla AM, Marco JD, Diosque P, Segura MA, Mora MC, Fernandez MM, Malchiodi EL, Basombrío MA, 2002. Canine infection and the possible role of dogs in the transmission of 
American tegumentary leishmaniosis in Salta, Argentina. Vet Parasitol 110: 1-10.

12. Evans D, 1989. Handbook on Isolation, Characterization, and Cryopreservation of Leishmania. Geneva: WHO, 1-45.

13. Hashiguchi Y, Gomez EAL, De Coronel VV, Mimori T, Kawabata M, Furuya M, Nonaka S, Takaoka H, Alexander JB, Quizhpe AM, Grimaldi G Jr, Kreutzer RD, Tesh RB, 1991. Andean leishmaniasis in Ecuador caused by infection with Leishmania mexicana and L. major-like parasites. Am J Trop Med Hyg 44: 205-217.

14. Kreutzer RD, Christensen HA, 1980. Characterization of Leishmania spp. by isozyme electrophoresis. Am J Trop Med Hyg 29: 199-208.

15. Bañuls AL, Jonquieres R, Guerrini F, Le Pont F, Barrera C, Espinel I, Guderian R, Echeverria R, Tibayrenc M, 1999. Genetic analysis of Leishmania parasites in Ecuador: Are Leishmania (Viannia) panamensis and Leishmania (V.) guyanensis distinct taxa? Am J Trop Med Hyg 61: 838-845.

16. Kumar S, Tamura K, Jakobsen IB, vNei M, 2001. MEGA2. Molecular evolutionary genetics analysis software. Bioinformatics 17: $1244-1245$.

17. Cupolillo E, Brahim LR, Toaldo CB, Oliveira-Neto MP, Felinto de Brito ME, Falqueto A, Farias Naiff M, Grimaldi G Jr, 2003. Genetic polymorphism and molecular epidemiology of Leishmania (Viannia) braziliensis from different hosts and geographic areas in Brazil. J Clin Microbiol 41: 3126-3132.

18. Schiriefer A, Shiriefer ALF, Góes-Neto A, Guimaraes LH, Carvalho LP, Almeida RP, Machado PR, Lessa HA, Ribeiro de Jesus A, Riley LW, Carvalho EM, 2004. Multiclonal Leishmania braziliensis population structure and its clinical implication in a region of endemicity for American tegumentary leishmaniasis. Infect Immun 72: 508-514.

19. Saravia NG, Segura I, Holguin AF, Santrich C, Valderrama L,
Ocampo C, 1998. Epidemiologic, genetic, and clinical associations among phenotipically distinct populations of Leishmania (Viannia) in Colombia. Am J Trop Med Hyg 59: 86-94.

20. Ishikawa EAY, Silveira FT, Magalhaes ALP, Guerra RB Jr, Melo MN, Gomes R, Siveira TGV, Shaw JJ, 2002. Genetic variation in populations of Leishmania species in Brazil. Trans $R$ Soc Trop Med Hyg 96: S1/111-S1/121.

21. Magalhaes-Rocha NM, Melo NM, Dias M, Michalick MSM, da Costa CA, Mayrink W, Williams P, 1989. Characterization of Leishmania strains isolated from dogs in an endemic area of Minas Gerais State-Brazil. Mem Inst Oswaldo Cruz 84 (SII): 41.

22. Cuba Cuba CA, Miles MA, Vexenat A, Barker DC, McMahon Pratt D, Butcher J, Barreto CA, Marsden PD, 1985. A focus of mucocutaneous leishmaniasis in Três Braços, Bahia, Brazil: characterization and identification of Leishmania stocks isolated from man and dogs. Trans $R$ Soc Trop Med Hyg 79: 500-507.

23. Vasconcelos IAB, Vasconcelos AW, Fe Filho NM, Queiroz RG, Santana EW, Bozza M, Sallenave SM, Valim C, David JR, Lopes UG, 1994. The identity of Leishmania isolated from sand flies and vertebrate hosts in a major focus of cutaneous leishmaniasis in Baturite, Northeastern of Brazil. Am J Trop Med Hyg 50: 158-164.

24. Rosa AC, Cuba CC, Vexenat A, Barreto AC, Marsden PD, 1988. Predominance of Leishmania braziliensis braziliensis in the regions of Três Braços and Corte de Pedra, Bahia, Brazil. Trans $R$ Soc Trop Med Hyg 82: 409-410.

25. Reithinger R, Davies CR, 1999. Is the domestic dog (canis familiaris) a reservoir host of American cutaneous leishmaniasis? A critical review of the current evidence. Am J Trop Med Hyg 61: 530-541. 